\title{
CURRÍCULO DE GEOGRAFIA DE TIMOR-LESTE: língua portuguesa como estratégia geopolítica e a significação de uma identidade nacional recente
}

\author{
Vanessa Lessio Diniz \\ Universidade Federal do Norte do Tocantins - UFNT, Brasil \\ Rafael Straforini \\ Universidade Estadual de Campinas - UNICAMP, Brasil
}

\begin{abstract}
Resumo
No presente artigo discutimos, no contexto histórico timorense pós-restauração da independência (2002-atual), o papel da Geografia escolar no âmbito da Reestruturação Curricular do Ensino Secundário Geral, entendendo essa disciplina enquanto prática espacial de significação que opera diretamente na construção de uma identidade nacional recente. Tendo como base uma perspectiva pós-crítica e pós-estruturalista, sob a ótica da Teoria do Discurso de Ernesto Laclau e Chantal Mouffe, compreendemos que a elaboração e a implementação do atual currículo de Timor-Leste estão carregadas de disputas discursivas entre contextos políticos, concepções institucionais e atores sociais envolvidos nesse processo. Metodologicamente, a partir da análise de entrevistas realizadas com interlocutores timorenses, constatamos que a língua portuguesa se apresenta como um importante componente da identidade nacional, de modo que se consolida na reestruturação curricular como um ponto nodal e um elemento geopolítico, visto que insere Timor-Leste na Comunidade dos Países de Língua Portuguesa (CPLP), numa tentativa estratégica de manutenção de uma ideia de nação frente aos seus vizinhos asiáticos e da Austrália.
\end{abstract}

Palavras-chave: Geografia escolar; Identidade nacional; Currículo; Teoria do Discurso; Ensino secundário.

\begin{abstract}
In the present article we discuss, in the timorese historical context after the restoration of independence (2002-present), the role of school geography in the context of the Curricular Restructuring of General Secondary Education, understanding this discipline as a spatial practice of meaning that operates directly in building a recent national identity. Based on a post-critical and post-structuralist perspective, from the perspective of Ernesto Laclau and Chantal Mouffe's Theory of Discourse, we understand that the elaboration and implementation of the current East Timor curriculum are fraught with discursive disputes between political contexts, institutional and social actors involved in this process. Methodologically, from the analysis of interviews conducted with Timorese interlocutors, we found that the portuguese language presents itself as an important component of national identity, so that it is consolidated in the curricular restructuring as a nodal point and a geopolitical element, as it inserts East Timor. East in the Community of Portuguese Speaking Countries (CPSC), in a strategic attempt to maintain an idea of nation in front of its Asian and Australian neighbors
\end{abstract}

Keywords: School geography; National identity; Curriculum; Discourse Theory; High school. 


\section{Introdução}

Tem-se acentuado, nos últimos anos, a influência das perspectivas discursivas pós-crítica e pós-estruturalista nas pesquisas que analisam o contexto de produção de documentos curriculares. Essas perspectivas passaram a fornecer um olhar mais complexo sobre a concepção de identidade cultural e social, permitindo assim a compreensão política do currículo para além das questões de classes sociais e das atividades econômicas do Estado (LOPES; MACEDO, 2011; MOREIRA, 2012; SILVA, 2015).

Pretendendo compreender a complexidade dos processos de misturas e de contatos entre grupos e nações, além da pluralidade que se dá contemporaneamente, utilizaremos a Teoria do Discurso proposta por Ernesto Laclau e Chantal Mouffe (LACLAU, 2002; LACLAU, 2011; LACLAU; MOUFFE, 2015; MENDONÇA; RODRIGUES, 2014) como suporte teórico-metodológico no direcionamento de nossas discussões. Essa teoria permite pensarmos a sociedade numa concepção relacional e discursiva, evitando o reducionismo, determinismo e existencialismo, utilizando-se de uma constelação de categorias ${ }^{1}$ para explicar fenômenos e eventos sociais. De antemão, afirmamos que as explicações das categorias hegemonia, pontos nodais, significante vazio e lógica da equivalência e da diferença, aqui destacadas, se darão na medida em que avançamos no texto, tomando ações práticas nas quais elas se evidenciam.

Segundo Lopes e Biglieri (2014), a Teoria do Discurso vem sendo incorporada à Educação e, dentro desse campo de conhecimento, mais centralmente ao campo do Currículo por intermédio de dois registros - a centralidade do político e a crítica aos fundamentos fixos do social. Tal incorporação se faz no âmbito do questionamento das próprias bases dos projetos educacionais da modernidade, provocando tensionamentos importantes na forma de compreender as finalidades educativas. Straforini e Lemos (2018, p. 95) discorrem, que o discurso para Laclau é entendido como um campo de práticas sociais “a Teoria do Discurso, por seu turno, não tem por objetivo encontrar convergências, traços comuns ou regularidades, mas sim compreender práticas de significação discursivas”, isto é, busca encontrar a inseparabilidade entre significação e a prática social.

Desse modo, este artigo trata-se de uma investigação sobre o atual currículo de Geografia de Timor-Leste, considerado por nós como uma construção social, que apresenta as intencionalidades de uma política educacional vigente a qual desempenha o papel de informar e formar sujeitos, difundindo o que uma dada hegemonia discursiva considera como verdade sobre um determinado assunto. Entendemos essa hegemonia como "uma relação em que um conteúdo particular assume, num certo contexto, a função de encarnar uma plenitude ausente” (LACLAU, 2002, p. 122).

Assim, buscamos compreender o papel da Geografia escolar no âmbito da Reestruturação Curricular do Ensino Secundário Geral de Timor-Leste, entendendo essa disciplina enquanto prática espacial de significação que opera diretamente na construção de uma identidade nacional recente. Segundo Straforini (2018), a Geografia escolar é uma prática espacial, uma vez que, sem essa prática, dificilmente as ideologias espaciais existiriam, já que os conteúdos presentes nos currículos dessa disciplina, construídos por 
grupos que articulam a construção de imaginários sobre um território ou nação, têm potencial político que produz significados, identidades e disputas. Contudo, evidenciamos a impossibilidade de completude para definirmos essa identidade nacional (mesmo com todas as tentativas e os discursos que levam a um imaginário de homogeneização e da padronização), dessa forma, atentaremos apenas para o modo como tal identidade é significada, negociada e reinventada.

Metodologicamente, aplicamos entrevistas semiestruturadas a diferentes interlocutores que, de alguma maneira, estavam relacionados à implementação do atual currículo de Geografia (Três professores de Geografia; o Diretor Geral do Departamento de Currículo o Ministério da Educação; e um pesquisador timorense da Faculdade de Educação, Artes e Humanidades da Universidade Nacional Timor Lorosa'e). O artigo está dividido em duas partes, cada uma delas com o objetivo de explicitar as cadeias articulatórias de equivalência e diferença em torno da oficialização da língua portuguesa em Timor-Leste como ponto nodal da reestruturação curricular no pós-independência e o papel da Geografia escolar na significação da identidade nacional timorense.

\section{O "imaginar" uma nação e a oficialização da Língua Portuguesa como estratégia geopolítica}

Timor-Leste foi colônia portuguesa entre 1515 e 1975, iniciando seu movimento de independência após a Revolução dos Cravos, ocorrida em 1974 em Portugal, que derrubou o regime salazarista, instituindo a democracia e abrindo espaço para a promoção das transformações sociais no país. Em 28 de novembro de 1975, o partido Frente Revolucionária de Timor-Leste Independente (FRETILIN) proclamou unilateralmente a independência do país. Porém, no dia 07 de dezembro de 1975, com a ajuda de partidos políticos que defendiam a anexação do território timorense ao indonésio, as forças militares indonésias, com o apoio dos Estados Unidos da América do Norte, invadiram Timor-Leste. A partir dessa data, a Indonésia ocupou o país por 24 anos, sendo esse período considerado um dos mais violentos e devastadores da sua história. Passando por um período de administração transitória organizada pela Organização das Nações Unidas (ONU), foi reconhecido como Estado soberano somente em 2002.

Refletindo sobre o contexto histórico timorense, com base em Schwarcz (2008), podemos atentar para o fato de que as nações não têm uma data de nascimento identificada apenas num registro oficial, mas que elas são, antes de tudo, imaginadas. Para a autora, esse exercício não é uma tarefa fácil, já que não se começa a imaginar uma nação no vazio e com base em nada, mas os seus

[...] símbolos são eficientes quando afirmam no interior de uma lógica comunitária afetiva de sentidos e quando fazem da língua e da história dados "naturais e essenciais"; pouco passíveis de dúvida e questionamento. O uso do "nós", presente nos hinos nacionais, nos dísticos e nas falas oficiais, faz com que o 
sentimento de pertença se sobreponha à ideia de individualidade e apague o que existe de "eles" e de diferença em qualquer sociedade (SCHWARCZ, 2008, p. 17).

Podemos pensar que Timor-Leste, mesmo tendo sua "data de nascimento oficial”, teve o ideal e a subjetividade de sua identidade nacional construídos, ou melhor, imaginados muito antes de sua libertação contra a Indonésia, uma vez que a ideia de nação é antes de tudo uma ideia - não uma realidade concreta - que supõe um estágio elevado de elaboração conceitual (VIDAL e SOUZA, 1997).

Convergindo com o conceito de protonacionalismo popular de Hobsbawn (1990), o qual considera que o sentimento de nacional surge antes mesmo da ideia de nação, para Paulino (2012, p. 02), o processo de construção da identidade nacional do povo de Timor-Leste teria começado, justamente, a partir da chegada dos portugueses há mais de 500 anos, com a constituição arbitrária das fronteiras terrestres do atual território

bem provável que, pela primeira vez, uma imensa diversidade de pequenos povos tenha começado a partilhar, primeiro, a estranheza, depois o incómodo e, finalmente, a revolta contra o invasor comum. Todavia, cada reino, ou grupo étnico, procurava reagir isoladamente e, de algum modo, a identidade do povo de Timor-Leste começou por ser, nesse tempo, uma pequena semente contendo já inscrito, qual código genético, o desígnio que fará dela uma planta frondosa sob a qual se acolhem hoje todos os timorenses.

Nessa mesma direção, Hobsbawm (1990) disserta sobre a possibilidade objetiva de caracterização de uma nação, alertando que os critérios utilizados costumam ser claros: língua, etnia, território comum e cultura. Ele defende, porém, que esses critérios são ambíguos, mutáveis e opacos e servem para fins propagandísticos e pragmáticos. Como solução à problemática da definição anterior, o autor aponta outra definição, dessa vez subjetiva, segundo a qual uma nação seria um corpo de pessoas suficientemente grande cujos membros se consideram parte de uma nação. Sendo assim, o necessário para se criar uma nação é simplesmente a vontade compartilhada de alguns indivíduos de sê-la (HOBSBAWN, 1990).

Nesse sentido, Anderson (1993), durante a ocupação indonésia, tentava compreender por que razão o regime de Suharto falhava na sua tentativa de integrar Timor-Leste como mais uma de suas províncias e como a forma autoritária desse regime contribuiu para que os timorenses pudessem imaginar a si próprios. Hall (2014, p. 109), concebendo as identidades enquanto construídas no interior dos discursos, nos alerta para o fato de que "precisamos compreendê-las como produzidas em locais históricos e institucionais específicos, no interior de formações e práticas discursivas específicas, por estratégias e iniciativas específicas”.

Durante a ocupação (1975-1999), o aprendizado da língua indonésia (bahasa indonesia) pelos timorenses foi obrigatório, assim como a proibição do uso da língua portuguesa em todo território. Isso ocorreu, principalmente, porque os oficiais do Estado indonésio não compreendiam o português, e a utilização dessa língua representava uma ameaça a seu 
controle e a sua governabilidade. Com o reconhecimento de Timor-Leste como Estado soberano em 2002, uma das primeiras ações políticas do governo, por meio da Assembleia Constituinte (composta por doze partidos políticos com assento proporcional), foi consagrar o tétum e o português como as línguas oficiais de Timor-Leste.

Segundo Corte-Real e Brito (2004, p. 124), desde a primeira hora da resistência (como ficou comprovado pelo Conselho Nacional de Resistência Timorense (CNRT), a organização supradirigente da luta conjunta pela autodeterminação e independência do território), “a língua oficial de Timor-Leste sempre foi o português, quer no mato, quer na diáspora, quer na clandestinidade que ligava as outras duas frentes da resistência (a armada e a diplomática)”. Nessa mesma direção, Silva (2017, p. 24-25) nos apresenta que a escolha do português como língua oficial deve-se ao fato de ter sido usado como forma de comunicação e resistência pelas Forças Armadas de Libertação Nacional de Timor-Leste (FALINTIL), com atuação dentro e fora de Timor-Leste, estando organizadas em três dimensões:

a) dimensão militar: liderada pelo então guerrilheiro Xanana Gusmão, que se ocupava da condução das táticas de guerrilha;

b) dimensão dos Direitos Humanos: conduzida pelo Bispo Dom Carlos Ximenes Belo, com respaldo da Igreja Católica e apoio popular;

c) dimensão política e diplomática: encabeçada por José Ramos Horta em sua ação internacional a partir de Portugal e da Austrália.

Em comum a essas três dimensões, havia a língua portuguesa, utilizada como elemento de coesão do movimento de resistência, o qual uniu a nação na luta contra o invasor.

Outro fator importante revelado pelo mesmo autor é que em Timor-Leste a adoção da língua portuguesa deve-se a critérios políticos: por um lado, foi a língua utilizada durante o processo de resistência contra o inimigo indonésio, conforme já destacamos, e, por outro, era a língua utilizada nas missas da igreja católica, instituição que teve papel fundamental na proteção dos timorenses durante os episódios de violência perpetrados pelo exército indonésio.

Ademais, na entrevista realizada com o Diretor Geral do Departamento de Currículo do Ministério da Educação, passamos a entender que a língua portuguesa também foi escolhida como língua oficial do currículo escolar de Timor-Leste por tratar-se de um instrumento importante para a promoção da ciência e do conhecimento do/no país. O diretor ressaltou que a escolha dessa língua

é o que nos distingue dos outros países da Ásia e da Austrália. Agora, se nós tivéssemos que usar a língua inglesa, não seríamos diferentes dos outros. Um dia, Timor-Leste reconhece sua posição e sua soberania, e defender sua pátria é difícil. Se falar língua indonésia não seremos diferentes da Indonésia, não teremos uma identidade própria para defendermos nossa identidade, nosso país, e nossa soberania. Então, a língua portuguesa foi crucial para Timor-Leste ser um país 
independente. Temos que defender essa língua (Entrevista realizada em agosto de 2017).

Compreendemos assim que no processo de constituição de uma identidade nacional a oficialização e utilização de uma língua pode agir como um ponto nodal, isto é, torna-se um dos principais elementos para a criação de um imaginário envolto de uma identidade comum. O pondo nodal pode ser compreendido como o significado mestre capaz de unificar uma superfície discursiva entrelaçando uma variedade de identidades diferentes em torno de um objetivo comum (SOUTHWELL, 2014; MARQUES, 2014). Ou seja, o ponto nodal é um termo que condensa ou que agrupa em torno de si um conjunto de sentidos, um significante privilegiado que fixa os sentidos de outros significantes na cadeia de significação (LACLAU, 2000, p. 165) e que é, assim, capaz de hegemonizar um dado conteúdo social.

Países recém-independentes quase sempre adotam a língua do antigo colonizador, mesmo com toda a carga histórica implicada nessa tomada de posição. Ao levar em consideração que a escolha de uma língua envolve disputas/relações de saber-poder, no caso timorense, essa situação vem sendo levada adiante (de forma bastante controversa) pela língua portuguesa que busca sua hegemonização, entretanto Laclau (2002) nos alerta que essa "hegemonia" será compreendida como uma relação em que uma determinada posição, em um determinado contexto histórico, de forma precária e contingente, passa a representar, a partir de uma relação equivalencial, múltiplos elementos.

Temos assim um forte discurso evidenciando a relação direta da língua portuguesa com a identidade nacional timorense. Esse contexto foi ressaltado durante as entrevistas com os interlocutores timorenses professores de Geografia:

Língua portuguesa é importante, porque é diferente da cultura com Indonésia, mas precisa muito esforço para ensinar em português, não são todos os professores que a dominam (Professor 1).

Ensinar em língua portuguesa é importante porque é língua oficial, é identidade, toda administração trabalha em língua portuguesa, os estudantes querem aprender (Professor 2).

Sobre a importância da língua portuguesa, apresentada pelos professores de Geografia, o timorense Luís Costa (2012), autor do Dicionário Tétum-Português, também argumenta que a escolha dessa língua como língua oficial contabiliza: um peso simbólico (por ser língua da resistência à invasão indonésia, língua usada para dar informações ao mundo sobre a luta e os efeitos da invasão); um aspecto identitário (o do seu passado sem grandes imposições, sem grande impacto); um aspecto afetivo (ligação ao catolicismo, igreja que em conflitos de guerra - segunda guerra mundial, invasão indonésia - nunca abandonou o povo); e um aspecto geoestratégico (Timor subordinado à Indonésia e à Austrália). Em relação a esse aspecto geoestratégico, o Diretor Geral do Departamento de Currículo também abordou que a língua portuguesa 
É geoestratégia, é segurança econômica, é tudo! Se vamos usar a língua portuguesa como nossa língua oficial, é que em Timor nós temos vários fantasmas. É que, primeiro, Timor-Leste é um país diferente dos outros países da Ásia, é uma identidade diferente, que é a Língua Portuguesa. (Entrevista realizada em agosto de 2017).

Notamos assim que esse Estado pós-independência vem sendo produzido a partir do embate entre distintos projetos civilizatórios, alimentados e executados estrategicamente pelas elites locais (SILVA, 2012), no qual evidencia-se mais uma vez o movimento de hegemonizar a importância da língua portuguesa no território timorense, evidenciando segundo Laclau (2002) um processo permanente de disputa, cujo objetivo é a fixação de determinados significados particulares, desejando que eles possam representar a totalidade.

Sobre a restauração da independência e oficialização das línguas, o intelectual timorense Antero Benedito da Silva (2016, p.155) expõe que Timor no pós-conflito foi reduzido a uma ideia de lugar vazio ou uma tabula rasa, referindo-se não meramente às infraestruturas em ruínas de um país pós-ocupado, mas também aos outros signos conotativos, tais como a ausência do sistema sociopolítico, econômico e também a ausência de conhecimento conforme o modelo eurocêntrico, ou seja, um "território da ausência, dessa forma não se permitiu naquele momento que houvesse contribuição de uma epistemologia timorense, já que na ausência não há nada a ser vislumbrado”.

O pesquisador Paulino (2018) discute que a sociedade timorense tem como objetivo a afirmação de sua existência enquanto estado-nação, e tal objetivo pode ser assegurado pelas quádruplas identidades: a língua portuguesa, o tétum, a fé católica e a cultura animista (cultura do lulik - que significa sagrado em língua tétum). Com isso, o autor, por meio de falas de pessoas importantes dentro do cenário político-histórico do país, reforça a argumentação de que todos os timorenses devem aprender a língua portuguesa:

É, por isso, que os timorenses devem aprender o português, pois disse Mari Alkatiri (dnoticia.pt, 10/6/2011): ela [a língua] não é do colonialismo, mas a língua do povo e não de qualquer regime político. É afirmar a identidade de Timor-Leste ligada à sua História, acrescenta ainda que "Se temos escolas de referência que estão a ter bons resultados, porque é que não ampliamos lentamente esse tipo de escolas, com o mesmo sistema de educação onde a língua portuguesa é usada como língua simultaneamente de ensino e de instrução desde a préescolar" (Mari Alkatiri, in Lusa, 4/3/2015). Rui Maria de Araújo, por sua vez, afirma que "Vamos todos apoiar esta ideia: Vamos todos dotar o Ministério da Educação de meios para poder ter professores em todas a escolas de Timor-Leste para ensinar português e em português” (Lusa, 7/5/2015) e não para implementar as línguas maternas. "Iremos, portanto, prosseguir os esforços e promover novas iniciativas no sentido de reforçar e promover a posição da língua portuguesa no sistema mundial, incluindo esforços de âmbito nacional, com a expansão do ensino da língua nas escolas de ensino privado, incluindo as escolas católicas e as universidades privadas” (Xanana Gusmão, in Lusa, 17/7/2014). Por isso, “não há razão para não utilizar a língua portuguesa” (Lobato, 2010) (Ibidem, 2018, p. 85). 
Ainda nesse sentido, segundo Almeida (2008), o fato de o governo atribuir a uma língua o status de oficial implicou uma série de ações concretas com vista à sua divulgação, seu ensino e seu uso. As duas línguas oficiais escolhidas traziam desde o início da autonomia timorense alguns problemas para a sua efetivação. $\mathrm{O}$ tétum, apesar de funcionar como uma língua franca, conhecida por boa parte da população, não era uma língua que permitia a comunicação internacional, sendo ainda pouco estudada e não tendo gramática oficial até $2002^{2}$. Dessa forma, foi necessário investir no estudo científico desta língua e no seu ensino formal nas escolas, já o português, apesar de ser uma língua internacional, não era uma língua nacional, isto é, apesar de ser falado por pessoas de outros países, em instituições internacionais, praticamente não era falado pelos timorenses.

Vale destacar, segundo Silva (2017), que existem grupos etnolinguísticos insatisfeitos com os rumos políticos e administrativos do país, como a adoção da língua portuguesa como idioma oficial. Esses reivindicam o direito legítimo de (re)significar sua existência frente às novas subjetividades individuais e coletivas, ou seja, evidencia-se as cadeias articulatórias da diferença.

Diante desses argumentos, evidencia-se a existência desse ponto nodal sobre a oficialização, (re)introdução e disseminação da língua portuguesa em todo o país como uma importante estratégia geopolítica e afirmação da identidade nacional. A construção de um currículo nacional em língua portuguesa é, para Timor-Leste, uma estratégia política, pois o uso dessa língua pós-independência marca a diferenciação cultural em relação ao antigo invasor indonésio, além de ser a sua porta de entrada para parcerias e cooperações diversas com o "mundo" lusófono, proporcionado pela sua entrada na Comunidade dos Países de Língua Portuguesa (CPLP). Segundo Diniz (2017), isso evidencia as cadeias articulatórias que perpassam a reestruturação curricular, ora marcada pela cadeia de diferença - que é a elaboração do currículo por estrangeiros portugueses -, ora marcada pela cadeia de equivalência em torno de um ponto nodal - que é a necessidade da disseminação da língua no país, permitindo essa elaboração dos currículos por estrangeiros. Nesse contexto, outras diferenças ficam dispersas no campo da discursividade, por exemplo, o ensino das línguas maternas; e a Cooperação Portuguesa acaba exercendo o papel do discurso dominante/hegemônico na construção desses currículos.

As cadeias articulatórias de equivalência e diferença refere-se à composição da construção de todos os discursos e das práticas articulatórias que fixam sentidos parciais, ao mesmo tempo em que mostram também os limites discursivos. A equivalência e a diferença estão relacionadas quando uma ou mais demandas particulares são capazes de assumir um sentido discursivo de outras demandas particulares, produzindo provisoriamente um discurso único que represente essas diferenças, logo, tornando-se universal (LACLAU (2011); PESSOA (2014); MENDONÇA E RODRIGUES (2014)). Nesse sentido, podemos dizer que o período da reforma curricular significa para Timor-Leste o esforço de manutenção de uma ideia de nação e de uma identidade nacional para as gerações que não vivenciaram o período de atrocidades e dominação. 
Por meio dos documentos curriculares, dos materiais didáticos e de uma cultura escolar nascente, essas ideias passam a povoar o imaginário do estudante e do cidadão timorense, fixando símbolos e princípios para a sustentação de um território genuinamente nacional, em que a língua portuguesa, na sua condição de ponto nodal, possibilitou uma complexa articulação de equivalência em prol desse sentimento de nacional. Sobre isso, Paulino (2018) afirma que a construção/criação do currículo nacional reflete precisamente aspectos da construção da identidade nacional e cultural timorense. Porém, esse autor também ressalta que a construção dessa identidade é compreendida como um processo aberto de construção e reconstrução infinita diante das necessidades que a nossa vida humana exige.

\section{Geografia escolar timorense e a significação de uma identidade nacional recente}

(Re)Conhecer a história das disciplinas escolares de um país pode proporcionar uma "outra” visão para os objetivos de ensino e de aprendizagem, pois assim torna-se possível desnaturalizar os conteúdos e os conhecimentos escolares, uma vez que, ao se falar de história das disciplinas, admitimos que essas são construções sócio-históricas, contextualizadas em tempos e espaços determinados e envoltas de interesses e de intencionalidades vinculadas aos seus contextos de produções (GOODSON, 1995; CHERVEL, 1990).

Nessa perspectiva, segundo Gomes (2000), a Geografia moderna origina-se no contexto de afirmação dos Estados nacionais europeus e do iluminismo, costurando na sua identidade enquanto ciência os discursos políticos e ideológicos próprios do contexto da modernidade. Goodson (1995) afirma que a Geografia como disciplina escolar também surge nesse período, muitas vezes anterior à própria Geografia como conhecimento cientificamente sistematizado. Para Moraes (1991), a Geografia teve grande importância e rápido desenvolvimento principalmente naqueles países que vivenciaram dificuldades de autoafirmação identitária num continente em que a definição das fronteiras dos estados-nação estava em aberto e, evidentemente, em disputas. Para esse autor, as teorias modernas dessa disciplina foram, em muito, veículos de legitimação das nacionalidades e dos respectivos projetos nacionais, uma vez que "o discurso geográfico foi, sem dúvida, um elemento central na consolidação do sentimento de pátria. Pode-se mesmo dizer que esse seria o principal núcleo divulgador da ideia da identidade pelo espaço" (p. 166).

Entende-se com base na Teoria do Discurso, que o discurso não está apenas relacionado à fala ou à escrita, mas a qualquer prática de significação, tão pouco pode ser compreendido como a imaterialidade da linguagem. Discurso é prática, uma vez que quaisquer ações empreendidas por sujeitos, identidades, grupos sociais são ações significativas (LOPES E MACEDO (2011); LACLAU (2011); SOUTHWELL (2014); MENDONÇA E RODRIGUES (2014)). 
Diante disso, pensando a construção, a reafirmação e a manutenção de uma identidade nacional timorense impulsionada pela disciplina de Geografia em Timor-Leste, acreditamos que o imaginário de nação pode ser significado por meio dessa disciplina escolar. De acordo com Straforini (2018), a ideologia, no que concerne à Geografia, não se restringe exclusivamente à Geografia escolar ou ao seu ensino, mas a todas as práticas espaciais ${ }^{3}$, que não só estão carregadas de ideologias, como elas próprias compõem um de seus conteúdos mais essenciais. No entanto, segundo o mesmo autor, ainda hoje existe uma prevalência inconteste de práticas espaciais hegemônicas na sociedade, porque o ensino de Geografia, enquanto uma prática espacial de significação discursiva, produz os discursos legitimadores dessas práticas hegemônicas.

Ou seja, essa disciplina, por meios das representações, dos signos e das significações presentes nos seus enunciados, atribui e carrega efeitos de verdade sobre a relação entre sociedade e natureza, abordando em seus currículos o entendimento e as correspondências de poder entre países e povos, o conhecimento da dinâmica da natureza para sua instrumentalização pela espécie humana e as diferentes matrizes culturais que também integram esse universo. Segundo Laclau (2011), a significação discursiva equivalência em relação à articulação de um significante e um significado, isto é, é o sentido social de determinado fenômeno.

Ressaltamos que a representação é uma parte essencial do processo pelo qual os significados são produzidos e compartilhados entre os membros de uma cultura, já que representar envolve o uso da linguagem, de textos, de símbolos, de signos e de imagens que se apresentam como "realidades", valores e identidades atribuídos a um determinado grupo social, povo e território. Assim, segundo Ribeiro (2006, p. 12), historicamente, a introdução da Geografia escolar em um país é analisada como integrante da formação da identidade nacional, da disciplina para a pátria e do nacionalismo.

A geografia escolar colabora assim, para a formação de um cidadão que permita o status quo de um governo ao desenvolver o sentimento de pertencimento a um grupo mais amplo. Entretanto, ainda hoje é relegado à Geografia o papel de construir no educando um sentimento de identidade nacional com base no território.

Vale destacar que os atuais currículos de Timor-Leste em língua portuguesa referentes à disciplina de Geografia foram elaborados e implementados por estrangeiros. Atualmente a Geografia enquanto disciplina escolar timorense está presente no Ensino Secundário Geral (ESG) e na grade curricular do curso de Hotelaria do Ensino Secundário Técnico Vocacional (ESTV). Já no $3^{\circ}$ Ciclo do Ensino Básico $\left(7^{\circ}, 8^{\circ}\right.$ e $9^{\circ}$ ano) o conhecimento geográfico não aparece como uma disciplina específica, mas está presente na disciplina de "História e Geografia”. Porém, em todo o país, ainda hoje não existem cursos superiores de formação de professores ou de bacharel em Geografia, o que demonstra uma realidade em que a maioria dos docentes não possuem formação específica nessa área. 
Buscando compreender o papel da Geografia escolar na reforma curricular de Timor-Leste no período pós-independência (2002), nos baseamos em Lopes (2011), que discorre que toda proposta de um currículo nacional tem a pretensão de homogeneidade de padrões e de saberes básicos a serem ensinados a todos. A autora salienta que ao longo da história dos currículos as finalidades desses saberes podem ser bem distintas, ora trata-se de saberes necessários ao mercado de trabalho, ora ao mundo tecnológico globalizado, à formação de uma elite dirigente, a uma cidadania crítica, a uma sociedade democrática, a uma perspectiva emancipatória e a inúmeros outros.

Nessa direção, é possível perceber que na atual proposta curricular de Geografia de Timor-Leste existe uma articulação com um projeto social mais amplo e que envolve uma concepção de sujeito e de educação a ser fomentada em detrimento de tantas outras possíveis. Segundo Leher (1999), o caráter determinante das ideologias que orientam uma reforma educacional fica mais bem evidenciado quando a investigação apresenta concretamente como as concepções ideológicas se materializam nas instituições que as elaboram.

Partindo dessas considerações, apresentamos brevemente que a reforma curricular do ESG, implementada em âmbito nacional, teve início no ano de 2010, quando o Ministério da Educação (ME) solicitou o apoio da Fundação Calouste Gulbenkian ${ }^{4}$ (FCG) para essa realização. A FCG e o Instituto Português de Apoio ao Desenvolvimento ${ }^{5}$ (IPAD), com o apoio técnico da Universidade de Aveiro (UA), apresentaram ao Fundo da Língua Portuguesa um projeto que foi aprovado para elaboração e implementação (RDTL, 2011). Com isso, concretizou-se o projeto de institucionalização do "Protocolo de Cooperação" assinado pelo $\mathrm{ME}$, pelo IPAD e pela FCG, no qual as responsabilidades dos envolvidos foram estabelecidas; também por um "Acordo de Cooperação” estabelecido entre a FCG e a UA, em que se delimitou os termos dos trabalhos que deveriam ser realizados.

Esse projeto foi denominado "Falar Português: Reestruturação Curricular do Ensino Secundário Geral em Timor-Leste”, que, sob a coordenação de Isabel Martins e de Ângelo Ferreira, tinha como objetivo não apenas elaborar o Plano Curricular para o ESG $\left(10 .^{\circ}, 11 .^{\circ}\right.$ e $12 .^{\circ}$ anos de escolaridade), mas também construir os programas para as catorze disciplinas do ESG e os recursos didáticos de apoio (Manuais para alunos e Guias para professores) para todos os anos de escolaridade. Para seu desenvolvimento, a equipe portuguesa integrou especialistas (portugueses) de todos os domínios disciplinares, com perfis diversos: professores do ensino superior e do ensino secundário, formadores de professores, especialistas em Didática, Ciências Exatas, Ciências Sociais, Línguas, Linguística, Literatura e Educação, autores de programas curriculares e manuais para alunos do sistema educativo português (MARTINS; FERREIRA, 2013).

O atual currículo do ESG é o resultado do projeto Reestruturação Curricular do Ensino Secundário Geral, desenvolvido entre janeiro de 2010 a março de 2013. O Plano Curricular do ESG foi aprovado em 2011, e os novos Programas começaram a ser implementados em fases e com sucessivos atrasos. Os materiais didáticos de apoio do $10^{\circ}$ ano foram distribuídos em pleno andamento do ano letivo de 2012, enquanto que o do $11^{\circ}$ e $12^{\circ}$ anos foram distribuídos simultaneamente no ano 2014. De acordo com relatos dos professores entrevistados, a distribuição dos manuais do aluno e guias do professor nas escolas 
apresentou bastante falha no processo. Os professores timorenses de Geografia também relataram em entrevistas vários desafios enfrentados na utilização desses manuais:

Para $10^{\circ}$ e $11^{\circ}$ anos têm manuais. O problema é que as turmas têm mais de sessenta alunos. Tenho uma turma com quase oitenta, então, não tem [material] para todos. Já para o $12^{\circ}$ ano não tem material, pois o governo entregou menos de dez manuais aqui na escola (Professor 1).

Hoje, uma grande dificuldade é a falta dos manuais. Por exemplo, para o $12^{\circ}$ ano, para Geografia, só temos três livros para os alunos. Para o $11^{\circ}$ há livros, mas para o $12^{\circ}$ não há. Aliás, quando o Ministério enviou para cá, na época, eram cinco ou seis manuais apenas. E depois, é claro, já fazem quatro ou cinco anos e esses livros vão desaparecendo e estragando. Então, os alunos só utilizam os manuais durante as aulas, depois são recolhidos (Professor 2).

Para $10^{\circ}$ ano tem muitos. Tem para todos. Mas os alunos só utilizam na escola, pois muitos não voltam. Mas, para o $11^{\circ}$ e $12^{\circ}$ tem muito pouco, e os alunos trabalham coletivamente com um manual para três ou quatro alunos. É muito difícil para discutir as imagens e trabalhar as atividades (Professor 3).

Observamos no texto do Plano Curricular (RDTL, 2011) que o ME havia considerado que a reestruturação e a elaboração dos programas das disciplinas escolares, dos manuais didáticos para os alunos e dos guias para os professores deveriam ser produzidas em articulação entre equipes homólogas de profissionais timorenses e portugueses.

A equipe da [Universidade de Aveiro] UA pôde beneficiar do apoio das autoridades políticas e técnicas do [Ministério da Educação] ME, bem como das informações e sugestões recolhidas localmente e oriundas dos mais diversos estratos sociais, económicos e culturais, e dos muitos professores timorenses escutados. [...] A elaboração dos instrumentos e dos materiais foi um trabalho complexo, que só foi possível pelas estreitas relações profissionais e pessoais que se estabeleceram entre as equipas da UA e as equipas homólogas timorenses e, também, pelas eficazes articulações institucionais desenvolvidas entre o ME, o IPAD, a FCG e a UA que permitiram a aprovação das matrizes orientadoras da concepção daqueles instrumentos e materiais, garantindo lhes coerência interna, estrutural e metodológica (RDTL, 2011, p. 04).

Porém, Ramos e Teles (2012) afirmam que a equipe portuguesa procurou aprofundar os conhecimentos sobre a realidade e a cultura timorense, inclusive a cultura escolar, mas não foi possível situar o mesmo nível de participação das equipes timorenses neste processo de elaboração e implementação das políticas educacionais pelos seguintes motivos: a carência de meio de comunicação, a falta de conhecimento na área específica das disciplinas e da língua portuguesa por parte dos timorenses e, por fim, a dificuldade do ministério timorense em efetivar a constituição da equipe timorense. Ou seja, de acordo com a equipe portuguesa, a não participação dos timorenses na reestruturação curricular ocorreu por "culpa dos próprios timorenses”, seja pela falta de domínio da língua portuguesa, seja pela falta de uma 
formação específica em determinada área, seja pela falta de organização do ministério; evidenciando-se a subalternização dos timorenses frente aos "especialistas portugueses" na produção desse documento.

No entanto, questionamos se esses especialistas (cooperação portuguesa), sabendo das dificuldades legítimas apresentadas pelos timorenses naquele contexto, não deveriam ter construído outros caminhos e metodologias para que os timorenses, com suas especificidades espaços-temporais, pudessem participar desse processo como protagonistas. Não deveriam ter criado outros espaços e condições de autorrepresentação, de questionamento dos limites representacionais, do lugar de enunciação dos timorenses? Com base em Spivak (2010), observamos que nesse processo antidialógico e verticalizado de reestruturação curricular, os timorenses são transformados em sujeitos subalternos, isto é, aqueles cuja vozes não podem ser ouvidas, permanecendo silenciadas e transfigurando-se mais em um "outro", destacandose a violência epistêmica como um projeto remotamente orquestrado, vasto e heterogêneo de se constituir o sujeito colonial como Outro.

Barbosa e Cassiani (2015) ressaltam que a não participação dos professores timorenses nesse processo de reestruturação tornou possível a problematização das interpretações e dos limites da configuração desses documentos curriculares, uma vez que esses apresentam aspectos que se equivalem ou se assemelham aos que são adotados em Portugal e, dessa forma, constituem-se documentos curriculares exóticos usados em sociedades ocidentalizadas e, principalmente, industrializadas, que na maioria das vezes não refletem a realidade timorense.

O currículo do ESG se organiza em torno de duas grandes áreas a saber: i) Ciência e Tecnologia e ii) Ciência Sociais e Humanidades. A Geografia está inserida como disciplina escolar no segundo itinerário, assim como também estão as disciplinas História, Sociologia, Temas de Literatura e Cultura, Economia e Métodos Quantitativos. A Geografia é ensinada nos três anos do ESG e possui uma carga horária semanal de 3h/aula. Segundo Bonito et al. (2014, p. 441), para a reestruturação da disciplina se pensou na

Geografia como disciplina autónoma que interliga as componentes física, económica, social e cultural, pretende contribuir para que os alunos possuam uma educação geográfica que lhes permita observarem o mundo que os rodeia de forma integrada, considerando o sistema Terra como um todo, onde o ser humano assume um papel fundamental no equilíbrio entre os sistemas naturais e os sistemas humanizados.

De acordo com Gomes et al. (2011), a disciplina de Geografia em Timor-Leste privilegia as caraterísticas, a estrutura e a dinâmica de cada componente (físico, social, econômico e cultural), bem como as interações que se estabelecem entre os diversos componentes, visando um estudo integrador e reflexivo das potencialidades de cada componente na busca de um desenvolvimento sustentável. Entretanto, a estrutura do "Programa de Geografia do $10^{\circ}, 11^{\circ}$ e $12^{\circ}$ ano de escolaridade" (quadro 1) se apresenta com percursos curriculares pré-definidos por três "Unidades Temáticas 
Quadro 1 - Esquema conceitual do programa da disciplina de Geografia para o Ensino Secundário Geral de Timor-Leste.

\begin{tabular}{|c|l|l|l|}
\hline $\mathbf{1 0}$ ano & $\begin{array}{l}\text { Unidade temática 1- } \\
\text { Timor-Leste, na Ásia e no } \\
\text { mundo }\end{array}$ & $\begin{array}{l}\text { Unidade temática 2- } \\
\text { As paisagens de Timor- } \\
\text { Leste }\end{array}$ & $\begin{array}{l}\text { Unidade temática 3- } \\
\text { Os recursos de Timor-Leste: } \\
\text { características, potencialidade e } \\
\text { ameaças } \\
\text {-Recursos naturais }\end{array}$ \\
\hline $\mathbf{1 1}$ ano & $\begin{array}{l}\text { Unidade temática 3- } \\
\text { Os recursos de Timor-Leste: características, potencialidade e ameaças } \\
\text {-Recursos humanos } \\
\text {-Recursos culturais }\end{array}$ \\
\hline $\mathbf{1 2}^{\mathbf{o}}$ ano & $\begin{array}{l}\text { Unidade temática 3- } \\
\text { Os recursos de Timor-Leste: características, } \\
\text { potencialidade e ameaças } \\
\text {-Recursos econômicos }\end{array}$ & $\begin{array}{l}\text { Unidade temática 4- } \\
\text { Ordenamento do território e gestão } \\
\text { sustentável de Timor-Leste }\end{array}$ \\
\hline
\end{tabular}

Fonte: Adaptado de Bonito et. al. (2014).

No caso dessa estrutura disciplinar, é possível notar uma função utilitária exercida pela geografia escolar para contribuir com os objetivos do Estado, evidenciada pelo forte discurso de desenvolvimento econômico e sustentável que se estabelece na construção do seu recente Estado-Nação. O programa da disciplina de Geografia para ESG tem como seu principal tema de discussão “Os recursos de Timor-Leste”. Esse apelo para representar Timor-Leste como "recurso" é um discurso em que o espaço geográfico timorense passa a ser entendido como meio físico, e esse é um dos fatores determinantes na construção de uma identidade nacional voltada para o desenvolvimento econômico. Tonini (2006, p.39), ao estudar a Geografia escolar no Brasil no período da primeira metade do século XX, afirma que a Geografia e o poder estatal sempre mantiveram fortes correlações, pois, "para melhor governar era imprescindível conhecer melhor o quadro natural, direcionando seu discurso para descrever os povos via natureza, pois esta era o elemento de normatização, já que todas as relações de poder eram explicadas pela natureza”.

Sobre o currículo de Geografia elaborado por mãos estrangeiras, os professores timorenses relatam:

O currículo do $11^{\circ}$ ano não corresponde com a realidade timorense, na formação nós falamos: 'professor Bernardo [cooperação portuguesa], isso não é realidade de Timor. Quem escreve essa matéria? Isso não é igual'. Sou formado em Agronomia, então, ajuda um pouco a reconhecer produtos de Timor, mas para os alunos fica difícil. (Professor 2)

O manual já está pronto, mas por exemplo, a posição do Monte Cablake está errada. Perguntamos para a professora: 'pode trocar?', e ela responde: 'não, não 
pode. Só daqui cinco anos, quando fizer a reformulação do currículo’ (Professor $3)$.

A partir desses enunciados, percebemos a relação antidialógica e vertical no processo de elaboração e implementação do atual currículo. Consideramos, com base em Freire (2014), que implementar um currículo não se trata simplesmente de transferir os conteúdos presentes no currículo escrito para dentro da sala de aula, tratando-o como se fosse algo pronto e acabado. Para esse autor, não podemos chegar a determinados contextos, à maneira da concepção bancária, e entregar-lhes conhecimentos contidos no programa, cujo conteúdo nós mesmos organizamos.

Na atualidade a disciplina de Geografia em Timor-Leste pouco avança ou contribui para a construção de práticas espaciais que propiciem a emancipação dos sujeitos, pois é marcada pela ausência de diálogos entre os conhecimentos ocidentais e as epistemes timorenses, evidenciando-se a busca por hegemonia da cooperação portuguesa no processo de fixação de sentidos geográficos, já que foram profissionais portugueses no âmbito da cooperação na área educacional que elaboraram os atuais currículos desse país. E praticamente todo conhecimento geográfico que busca fixar-se nesse território é descontextualizado da realidade local, da história e do imaginário geográfico que os timorenses têm de mundo e da relação desse imaginário com o seu mundo.

Nessa direção, pensando a Geografia escolar enquanto uma prática espacial de significação, podemos dizer que os enunciados pertencentes à atual Geografia escolar timorense, por meio de sentidos discursivos de território como recurso, produzidos pela Cooperação Portuguesa e inseridos nos conteúdos curriculares, agem no processo de significação do imaginário de território e de nação, suturando uma identidade nacional dos jovens timorenses aos recursos a serem explorados em detrimento de outros sentidos discursivos que foram interditados nesse momento de produção curricular, a exemplo da “epistemologia timorense”, como vem defendendo atualmente Silva (2016). Ressaltamos, mais uma vez, que um documento curricular não pode ser considerado somente um “depósito” de conteúdo, “[...] um lugar em que os autores registram os conhecimentos geográficos, mas também, [...], como um lugar de produção de significados, como um artefato cultural no qual as verdades são fabricadas e postas em circulação” (TONINI, 2006, p. 32). Nessa direção, o pesquisador Vicente Paulino nos alerta,

O currículo está aí! E demorou para sair, e ainda hoje não está em todos as escolas do país de forma igual. Desde 2012, os professores estão tentando trabalhar com esse material, tendo dificuldades com língua e com os conteúdos. O governo também gastou muito dinheiro para implementar esse currículo, então, não podemos simplesmente jogar fora. Precisamos avaliar os erros, reformular e timorizar os conteúdos (Entrevista realizada em novembro de 2017).

Nesse sentido, a partir da análise do processo de produção e de implementação do currículo, bem como da Geografia presente nele, podemos afirmar que a identidade timorense pode ser entendida como um significante vazio (LACLAU, 2011), uma vez que está em 
constante disputa por significação, resultado das cadeias articulatórias de diferença e equivalência em torno do currículo escolar. É um significante que em diferentes formações discursivas presentes no currículo de Geografia assume sentidos diferenciados, visando atender a demandas específicas de um determinado tempo-espaço da sociedade. Percebemos assim que a identidade timorense recente está sendo construída, ora marcada pela língua portuguesa, ora marcada pela estratégia geopolítica de diferença cultural com o colonizador, ambas alimentadas nos enunciados do atual currículo de Geografia do ESG como território recurso.

\section{Considerações}

Sob a perspectiva da Teoria do Discurso de Ernesto Laclau e Chantal Mouffe, compreendemos o currículo como discurso, assim, é necessária uma trajetória de análise que nos coloca além das palavras, passando a considerar contextos, sujeitos e sentidos que vão se suturando nas práticas sociais. Nessa perspectiva teórica, consideramos que no currículo de Geografia em Timor-Leste não existe um sentido previamente fixado e totalizante, mas um currículo que se configura como um processo de produção de sentidos, sempre híbridos, que nunca cessa e que, logo, proporciona uma infinita necessidade de significação.

Avançando nessa discussão, compreendemos a reestruturação curricular do Ensino Secundário Geral como um movimento antidialógico e verticalizado, já que os profissionais portugueses no âmbito da cooperação na área educacional elaboraram os atuais currículos do país. Desse modo, observamos que os conhecimentos geográficos que circulam em instituições de ensino são descontextualizados ou desconectados da realidade local do país, da história e do imaginário geográfico que os timorenses têm com o seu mundo.

Nesse caminho, a Geografia escolar enquanto prática espacial de significação implica pensar o currículo dessa disciplina como um processo amplo e complexo, sobretudo transpassado pelas rápidas transformações que ocorrem no atual estágio da globalização. Partindo desse ponto de vista, consideramos que na atualidade a Geografia escolar de Timor-Leste pouco avança ou contribui para a construção de práticas espaciais que propiciem a emancipação dos sujeitos timorenses, já que esta é marcada pela ausência de diálogos entre conhecimentos ocidentais (impostos via reforma curricular) e epistemes/contextos de Timor-Leste, fixando, ainda que provisoriamente, a hegemonia da cooperação portuguesa no processo de fixação de sentidos geográficos.

A partir da análise das entrevistas realizadas com os interlocutores timorenses, consideramos que a língua portuguesa sutura uma identidade nacional timorense por se tratar de um ponto nodal importante no contexto de sua autonomia e existência enquanto Estado autônomo. Nesse sentido, a língua portuguesa se fixa como língua oficial escolar e se consolida na reestruturação do currículo do ESG como um elemento geoestratégico, ou seja, insere Timor-Leste como um país diferente dos outros vizinhos asiáticos (por exemplo, o antigo invasor indonésio) e da Austrália. Os argumentos dos interlocutores timorenses, apontando que Timor-Leste é assegurado enquanto estado-nação pela língua portuguesa, 
denunciam a existência de um ponto nodal, isto é, a (re)introdução e disseminação dessa língua em todo o país se apresenta como uma importante estratégia geopolítica de afirmação da identidade nacional e de manutenção de uma ideia de nação.

Assim, consideramos essas palavras não como a finalização de uma ideia, mas como considerações que representam (in)conclusões e reflexões dentro de um movimento de pensar e fazer currículo, que buscou compreender, sob a ótica da Teoria do Discurso, como a Geografia escolar timorense, enquanto uma prática espacial de significação, tem relação com a construção e a manutenção de uma identidade nacional recente.

\section{Notas}

1. As principais categorias analíticas da Teoria de Discurso são exploradas no livro "Emancipação e Diferença" (LACLAU, 2011, p. 47-105).

2. Segundo Hull e Eccles (2005), com a promulgação da Constituição Nacional, no dia 20 de maio de 2002, que elevou o tétum à posição da língua oficial, os dirigentes de Timor-Leste tornaram a padronização do tétum uma das suas prioridades. Para este fim, foi inaugurado o Instituto Nacional de Linguística (INL) da Universidade Nacional Timor Lorosa'e em 2001, sendo dada pelo governo de Timor-Leste ao INL a importante tarefa de coordenar a estandardização da língua nacional. A política de planejamento linguístico do INL ocorreu com dois princípios: o reconhecimento do tétum-praça como a base da língua literária nacional; a exclusão da linguagem literária padronizada das efêmeras estruturas e palavras importadas do malaio-indonésio, dando-se preferência aos termos tétum genuínos ou de origem portuguesa. Dessa forma, nota-se que foi somente a partir da oficialização desta língua que se iniciou sua padronização e a publicação dos primeiros livros de gramática da língua tétum.

3. "Práticas espaciais são práticas sociais em que a espacialidade (a organização espacial, a territorialidade, a "lugaridade") é um componente nítido e destacado de forma de organização, do meio de expressão e/ou dos objetos a serem alcançados (SOUZA, 2013, p. 241)”.

4. A Fundação Calouste Gulbenkian é uma instituição portuguesa de direito privado e utilidade pública geral com caráter perpétuo, cujos fins estatutários são a Arte, a Beneficência, a Ciência e a Educação. Criada por disposição testamentária de Calouste Sarkis Gulbenkian, que legou os seus bens ao país sob a forma de uma fundação, os seus estatutos foram aprovados pelo Estado Português a 18 de julho de 1956 (Informação disponível em:<https://gulbenkian.pt/ >. Acesso em 14 de novembro de 2018).

5. O Instituto Português de Apoio ao Desenvolvimento (IPAD) é uma agência do Ministério dos Negócios Estrangeiros de Portugal. Desde 2003, o IPAD é responsável pela coordenação, supervisão e direção da assistência oficial de Portugal aos países em desenvolvimento. O instituto concentra-se nos países africanos de língua portuguesa (Angola, Cabo Verde, Guiné-Bissau, Moçambique e São Tomé e Príncipe, conhecidos em Português pela sigla PALOP) e em Timor Leste (Informação disponível em:< https://www.devex.com/organizations/instituto-portugues-de-apoio-ao-desenvolvimento-44707 >. Acesso em 14 de novembro de 2018).

\section{Referenciais}

ALMEIDA, Nuno Carlos Henrique de. Língua Portuguesa em Timor-Leste: Ensino e Cidadania. Dissertação de Mestrado. Universidade de Lisboa, 2008.

ANDERSON, Benedict. Imaginando Timor-Leste. Tradução de Osvaldo Manuel Silvestre. Reproduzido de 
Ciberkiosk e de Arena Magazine 4, 1993. Disponível em: <https://www.udc.es/dep/lx/cac/sopirrait/sr075.htm>. Acesso em: 10 de maio de 2018.

BARBOSA, Alessandro Tomaz; CASSIANI, Suzani. Efeitos de colonialidade no currículo de ciências do ensino secundário em Timor-Leste. Revista Dynamis. FURB, Blumenau, v.21, n. 1, p. 3-28, 2015.

BONITO, Jorge; REBELO, Dorinda; MORGADO, Margarida; GOMES, Conceição; COELHO, Celeste; ANDRADE, António Soares de; MARQUES, Luís. Contributos da reforma curricular em Timor-Leste para a literacia do cidadão em Ciências da Terra. Terræ Didatica, 2014.

CHERVEL, André. História das disciplinas escolares: reflexões sobre um campo de pesquisa. Teoria e Educação, 2, p.177-229, 1990.

CORTE-REAL, Benjamim de Araújo; BRITO, Regina Helena Pires de. Aspectos da política linguística de Timor-Leste: desvendando contracorrentes. Atas do X Congresso Brasileiro de Língua Portuguesa. Pontifícia Universidade Católica, São Paulo, 2004.

COSTA, Luís. A língua. Fator de identidade nacional leste-timorense. In: BASTOS, Neusa Barbosa.(org.) Língua portuguesa: aspectos linguisticos, culturais e identitários. São Paulo: EDUC, 2012.

DINIZ, Vanessa Lessio. A Reestruturação do Currículo de Geografia em Língua Portuguesa de Timor-Leste: contradições e desafios na sua implementação. Anais dos XII Colóquio sobre Questões Curriculares. Universidade Federal de Pernambuco, Recife, 2017.

FREIRE, P. Pedagogia do Oprimido. 58 ${ }^{a}$ ed. Rio de Janeiro: Paz e Terra, 2014.

GOMES, Conceição; MORGADO, Margarida; COELHO, Celeste. Programa. Geografia - Ensino Secundário Geral. Díli: Ministério da Educação de Timor-Leste. URL: https://www.ua.pt/ReadObject.aspx?obj=28435. 2011.

GOODSON, Ivor. Currículo: teoria e história. Petrópolis: Vozes, 1995.

HALL, Stuart. Quem precisa de identidade? In: SILVA, Tomaz Tadeu da; HALL, Stuart; WOODWARD, Kathryn. (Orgs.). Identidade e Diferença: A perspectiva dos Estudos Culturais. 15. ed. - Petrópolis, Rio de Janeiro: Vozes, 2014.

HOBSBAUM, Eric. Nações e Nacionalismo desde 1780: programa, mito e realidade. Tradução: Maria Celia Paoli e Anna Maria Quirino. Rio de Janeiro: Paz e Terra, 1990.

HULL, Geoffrey; ECCLES, Lance. Gramática da Língua Tétum. Editora Lidel, 2005.

LACLAU, Ernesto. Misticismo, retórica y política. Buenos Aires. Fondo de Cultura Económica, 2002.

LACLAU, Ernesto. Emancipação e diferença. Rio de Janeiro: EdUERJ, 2011.

LACLAU, Ernesto; MOUFFE, Chantal. Hegemonia e estratégia socialista: por uma política democrática radical. Tradução: Joanildo Burity, Josias de Paula Jr. e Aécio Amaral. São Paulo: Intermeios (Coleção Contrassensos). Brasília: CNPq, 2015.

LEHER, Roberto. Um Novo Senhor da Educação? A política educacional do Banco Mundial para a periferia do capitalismo. Revista Outubro. São Paulo, v. 1, n. 3, p. 19-30, 1999.

LOPES, Alice Casimiro. Políticas de Currículo: questões teórico-metodológicas. In: LOPES, Alice Casimiro; DIAS, Rosanne Evangelista; ABREU, Rozana Gomes de (Orgs.). Discursos nas políticas de currículo. Rio de Janeiro: Quartet, 2011.

LOPES, Alice Casimiro; BIGLIERI, Paula. Estudos interdisciplinares em Teoria do Discurso. Projeto de pesquisa do grupo Currículo: sujeitos, conhecimento e cultura da Universidade Estadual do Rio de Janeiro - $\quad$ UERJ, 2014. Disponível em: <http://www.curriculouerj.pro.br/imagens/pdfProj/estudos_in_27.pdf>. Acesso em: 15 de outubro de 2018.

LOPES, Alice Casimiro; MACEDO, Elizabeth. Teorias de Currículo. São Paulo: Cortez, 2011.

MARQUES , Luciana Rosa. Contribuições da democracia radical e da teoria do discurso de Ernesto Laclau ao estudo de gestão da educação. In: MENDONÇA, Daniel de; RODRIGUES, Leo Peixoto (Orgs.). Pós- 
estruturalismo e Teoria do Discurso: em torno de Ernesto Laclau. Porto Alegre: EdiPUCRS, 2014.

MARTINS, Isabel; FERREIRA, Ângelo. A Reestruturação Curricular do Ensino Secundário Geral em Timor Leste: um caso de cooperação da Universidade de Aveiro no domínio da educação. In: Morais, Carlos; Coimbra, Rosa Lídia (Orgs.). 3. ${ }^{\circ}$ Congresso Internacional "Pelos mares da língua portuguesa". Universidade de Aveiro, 2013.

MENDONÇA, Daniel de; RODRIGUES, Leo Peixoto. Em torno de Ernesto Laclau: pós-estruturalismo e teoria do discurso. In: MENDONÇA, Daniel de; RODRIGUES, Leo Peixoto (Orgs.). Pós-estruturalismo e Teoria do Discurso: em torno de Ernesto Laclau. Porto Alegre: EdiPUCRS, 2014.

MORAES, Antônio Carlos Robert. Notas sobre identidade nacional e institucionalização da geografia no Brasil. Estudos históricos. Rio de Janeiro, vol. 4, n. 8, 1991.

MOREIRA, Antonio Flavio Barbosa. Currículo, utopia e pós-modernidade. In: MOREIRA, Antonio Flavio Barbosa (Org.). Currículo: questões atuais. - 18aad. - Campinas, SP: Papirus, 2012.

PAULINO, Vicente. Currículo nacional de ensino de Timor-Leste como um problema a resolver. In: FONSECA, Sabina da; BAPTISTA, Maria do Céu; Araújo, Irta Sequeira Baris de. Desafios da Educação em Timor-Leste: Responsabilidade social. Unidade de Produção e Disseminação do Conhecimento do Programa de Pós-Graduação e Pesquisa da UNTL, 2018.

PAULINO, Vicente. Representação identitária em Timor-Leste Culturas e os Media. Tese de Doutorado em Ciências da Cultura. Faculdade De Letras, Universidade De Lisboa, Lisboa, 2012.

RAMOS, Ana Margarida; TELES, Filipe. Memória das políticas educativas em Timor-Leste: A consolidação de um sistema (2012-2017). Editora da Universidade de Aveiro, 2012.

RDTL, República Democrática de Timor-Leste. Plano Curricular do Ensino Secundário Geral. Ministério da Educação. Díli, 2011.

RIBEIRO, Wagner Costa. Prefácio. In: TONINI, Ivaine Maria. Geografia escolar: uma história sobre seus discursos pedagógicos. 2. ed. - Ijuí: Ed. Unijuí, 2006.

SCHWARCZ. Lilia Moritz. Imaginar é difícil (porém necessário). In: ANDERSON, Benedict. Comunidades imaginadas: reflexões sobre a origem e a difusão do nacionalismo. São Paulo: Companhia das Letras, $4^{\mathrm{a}}$ reimpressão, 2008.

SILVA, Alexandre Marques. Resistir é vencer: a construção da identidade leste-timorense no discurso de resistência de Xanana Gusmão. In: GONÇALVES-SEGUNDO, Paulo Roberto et al. (orgs.) Texto, discurso e multimodalidade: perspectivas atuais. VII EPED - Encontro de Pós-Graduandos em Estudos Discursivos da USP. Editora Paulistana, São Paulo, 2017.

SILVA, Antero Benedito da. Educação Timoriana: uma proposta alternativa. In: PAULINO, Vicente Paulino; BARBOSA, Alessandro Tomaz (orgs.) Língua, Ciência e Formação de Professores em Timor-Leste. Unidade de Produção e Disseminação do Conhecimento e Programa de Pós-Graduação e Pesquisa da UNTL, Díli, 2016.

SILVA, Kelly Cristiane da. As nações desunidas: práticas da ONU e a estruturação do Estado em TimorLeste. Belo Horizonte: Editora UFMG, 2012.

SILVA, Tomaz Tadeu da. Documentos de identidade: uma introdução às teorias de currículo. Belo Horizonte: Autêntica, 2015.

SOUZA, Marcelo Lopes de. Práticas Espaciais. In: espacial. Rio de Janeiro: Bertrand Brasil, 2013 Os conceitos Fundamentais da Pesquisa Sócio-

SPIVAK, Gayatri Chakravorty. Pode o subalterno falar? Belo Horizonte: Editora UFMG, 2010.

STRAFORINI, Rafael. O ensino de Geografia como prática espacial de significação. Revista Estudos Avançados. n³2 (93), 2018.

TONINI, Ivaine Maria. Geografia Escolar: uma história sobre seus discursos pedagógicos. 2.ed. - Ijuí: Ed. 
Unijuí, 2006.

VIDAL E SOUZA, Candice. A pátria geográfica: sertão e litoral no pensamento social brasileiro. Goiânia: Ed. da UFG, 1997.

\section{Correspondência}

Vanessa Lessio Diniz: Doutora em Geografia pela Universidade Estadual de Campinas (Unicamp); mestre em Ensino e História de Ciências da Terra e Graduada em Geografia pela mesma universidade. Professora do Colegiado de Geografia (campus Araguaína) e do Programa de Pós-Graduação em Estudos de Cultura e Território da Universidade Federal do Norte do Tocantins (UFNT).

E-mail: vanessalessiodiniz@gmail.com

Orcid: https://orcid.org/0000-0002-1088-6314

Rafael Straforini: Doutor em Geografia pela Universidade Federal do Rio de Janeiro (UFRJ); mestre em Educação Aplicada às Geociências (Unicamp) e Graduação em Geografia pela Universidade Estadual Paulista (Unesp), Campus de Rio Claro. Professor do Departamento de Geografia e do Programa de PósGraduação em Geografia da Unicamp. Editor-chefe da Revista Brasileira de Educação em Geografia.

E-mail: strafo@unicamp.br

Orcid: https://orcid.org/0000-0002-6122-3297

Texto publicado em Currículo sem Fronteiras com autorização dos autores. 